\title{
MULHERES CRIMINOSAS E A GUERRA DAS FRONTEIRAS: UMA ANÁLISE PSICOSSOCIAL
}

\author{
CRIMINAL WOMEN AND THE BORDER WAR: A PSYCHOSOCIAL ANALYSIS
}

LAS MUJERES DELINCUENTES Y LA GUERRA DE LAS FRONTERAS: UN ANÁLISIS PSICOSOCIAL

Sonia Regina Vargas Mansano*

Flávia Fernandes de Carvalhaes*

Maria Juracy Filgueiras Toneli ${ }^{* * *}$

\begin{abstract}
RESUMO
Este artigo problematiza as maneiras como, entre os anos de 2000 e 2013, mulheres acusadas ou julgadas por crimes foram enunciadas na mídia impressa brasileira. A análise percorreu a construção social de quatro configurações subjetivas que estiveram presentes no cenário midiático: a vítima, a desequilibrada, a primeira-dama e a emancipada. Tendo como pano de fundo o debate das questóes de gênero e da ordem capitalista hegemônica, adotou-se a cartografia como estratégia de investigação. Concluiu-se que a mídia está conectada a campos vivos e tensionados de forças, em que premissas tanto conservadoras quanto subversivas de gênero são produzidas.
\end{abstract}

Palavras-chave: Gênero. Crime. Mídia. Mulheres. Cartografia.

\begin{abstract}
This article discusses how, between the years of 2000 to 2013, women accused or tried for crimes were reported in Brazilian print media. The analysis covered the social construction of four subjective configurations that were present at the media scenario: the victim, the unbalanced, the first lady, and the emancipated. Against the background of the debate regarding issues of gender and the hegemonic capitalist order, cartography was adopted as a research strategy. It was concluded that the media is connected to live and tensioned fields of forces, in which both conservative and subversive gender assumptions are produced.
\end{abstract}

Keywords: Gender: Crime. Media. Women. Cartography.

\footnotetext{
Texto recebido em 22 de fevereiro de 2017 e aprovado para publicação em 23 de abril de 2018.

*Doutora em Psicologia Clínica pela Pontifícia Universidade Católica de São Paulo (PUC-SP), docente no Programa de Pós-Graduação em Administração, no Programa de Pós-graduação em Psicologia e no Departamento de Psicologia Social e Institucional da Universidade Estadual de Londrina (UEL).E-mail: mansano@uel.br

** Doutora em Psicologia pela Universidade Federal de Santa Catarina (UFSC), docente no Programa de Pós-graduação em Psicologia e no Departamento de Psicologia Social e Institucional da UEL.E-mail: fcarvalhaes@uel.br

${ }^{* * *}$ Doutora em Psicologia Escolar e do Desenvolvimento Humano pela Universidade de São Paulo (USP), docente no Programa de Pós-Graduação e no Curso de Graduação em Psicologia na UFSC. E-mail: juracy.toneli@gmail.com
} 


\section{RESUMEN}

Este artículo aborda las formas como, entre los años 2000 y 2013, las mujeres acusadas o juzgadas por delitos figuraban en los medios impresos brasileños. El análisis cubrió la construcción social de cuatro configuraciones subjetivas que estuvieron presentes en el campo mediático: la víctima, la desequilibrada, la primera dama y la emancipada. En el contexto del debate de las cuestiones de género y del orden capitalista hegemónico, la cartografía fue utilizada como estrategia de investigación. Se concluyó que los medios de comunicación se relacionan con campos de fuerza vivos y tensos donde se producen tanto concepciones conservadoras como subversivas del género.

Palabras clave: Género. Delito. Medios de comunicación. Mujeres. Cartografía.

\section{INTRODUÇÃO}

A multiplicidade de imagens e discursos que retratam os modos de viver presentes na sociedade contemporânea permite a experimentação de novas Isensações e representações, ao mesmo tempo em que nos interpelam a questionar sobre modos conservadores de vida. Tais arranjos interferem na (re) produção de velhas e novas expressões subjetivas e sociais, que se apresentam cada vez mais difusas, complexas e plurais. Exemplo disso pode ser encontrado no aumento do índice de mulheres envolvidas em práticas criminosas (Avansini, 2012). Tal constatação embaralha as fronteiras de gênero, que associam o feminino a premissas de docilidade, fragilidade e passividade, e o masculino, à racionalidade, agressividade e atividade (Butler, 2003).

Buscando problematizar essa temática, este artigo objetiva analisar alguns enunciados presentes na mídia impressa brasileira, em notícias sobre mulheres tidas como criminosas. $\mathrm{O}$ conceito de enunciado aqui utilizado encontra suporte na obra de Foucault (1969/1986), ${ }^{1}$ sendo compreendido como produção histórica e política, que demanda uma análise situada. Para tanto, a investigação trilha o seguinte caminho: primeiramente, serão apresentados os pressupostos metodológicos e teóricos da pesquisa. Em seguida, são analisadas as maneiras como, entre os anos de 2000 a 2013, alguns crimes investigados e atribuídos a mulheres foram descritos na mídia impressa brasileira, possibilitando a emergência de quatro composições subjetivas: a vítima, a desequilibrada, a primeira-dama e a emancipada.

\footnotetext{
${ }^{1}$ A primeira data indica o ano de publicação da obra, e a segunda, a edição consultada pelo autor, a qual somente será pontuada na primeira citação da obra no texto. Nas seguintes, será registrada apenas a data de publicação original.
} 
O trabalho justifica-se por dar evidência aos enunciados que rompem com representação hegemônica de gênero, que atribui aos homens a força e às mulheres a fragilidade. Ao fim do trabalho, será possível evidenciar o quanto as fronteiras de gêneros mais tradicionais entram em guerra com os novos modos de subjetivação inventados no contemporâneo e são colocadas em xeque, exigindo novas leituras sobre a existência.

\section{PRESSUPOSTOS METODOLÓGICOS E TEÓRICOS}

Esta investigação encontrou aporte metodológico na denominada cartografia (Deleuze, \& Guattari, 1996). Esta foi utilizada como um dispositivo analítico que possibilitou a construção de conexões e agenciamentos nos processos de seleção e problematização dos enunciados destacados de jornais e revista no Brasil. O processo cartográfico implica em uma reversão metodológica: a de que o pesquisador se guie pelos caminhos que se desenham ao longo da investigação, buscando mapear as condiçôes que possibilitaram a emergência social de determinados discursos em um momento histórico delimitado (Barros, \& Kastrup, 2015). Assim, não buscamos "desvelar" enunciados que implicassem "verdades" subjacentes às mulheres criminosas brasileiras, e sim rastrear pistas e traçados que, nos discursos jornalísticos, vêm se articulando na produção de noções estereotipadas sobre seu envolvimento com a criminalidade. Desse modo, consideramos que "a pesquisa cartográfica consiste no acompanhamento de processos, e não na representação de objetos” (Barros, \& Kastrup, 2015, p. 53).

A coleta de dados se deu por meio do acervo digital disponibilizado pelos jornais Folha de São Paulo, O Estado de São Paulo, Jornal do Brasil e O Globo, bem como da revista Veja, em que constam arquivadas notícias veiculadas em jornais e revistas de grande e média circulação no Brasil. O mapeamento realizado se restringiu aos anos de 2000 a 2013 e ocorreu por meio de buscas pautadas em palavras-chave tais como: presa, detenta, traficante, sequestradora, homicida, criminosa e dama do pó. Ao todo, foram selecionadas 121 reportagens sobre o envolvimento de mulheres em crimes diversos. Dessas reportagens, foram selecionados fragmentos de acordo com as quatro personagens delimitadas como unidades de análise: a vítima, a desequilibrada, a primeira-dama e a emancipada. A escolha por esses veículos pautou-se no fato de eles terem ampla circulação no Brasil, ainda que atinjam, sobretudo, camadas socioeconômicas privilegiadas do País. Outra questão que norteou a escolha por esses veículos de comunicação foi o fato de serem os jornais e a revista em que mais se evidenciaram reportagens sobre crimes cometidos por mulheres no período delimitado. 
Discursos e imagens veiculados na mídia se organizam como forças que se pretendem regulatórias, constituídas em torno de "uma espécie de poder produtivo, o poder de produzir - demarcar, fazer, circular, diferenciar - os corpos que controla" (Butler, 2001, p. 154). Butler (2003) e Preciado (2008) afirmam que os processos pelos quais se constroem perspectivas tradicionais de gênero estão alicerçados na premissa de que o corpo é uma estrutura natural e que carrega "verdades" ocultas. Marcados por uma divisão sexual, macho ou fêmea, que encontra aporte em explicaçôes anatômicas e hormonais, os corpos são caracterizados como bases passivas em que um conjunto de significados culturais vai se instalar. Nesse tipo de análise, os gêneros são considerados produções sociais, contudo estes são avaliados com base em um determinismo linguístico (e biomédico) que estabelece uma conexão binária e universal entre macho/masculino/ativo e fêmea/feminino/passivo.

Entretanto, o sujeito não se constrói apenas com base nesse parâmetro. Masculinidades e feminilidades são também produzidas em uma trama de condições heterogênea, interseccionadas a modalidades raciais, de classe, étnicas, sexuais e regionais, resultando em desenhos plurais e diferenciados de uma cartografia mutante. Tem-se, portanto, um sujeito "múltiplo em vez de único, e contraditório em vez de simplesmente dividido" (De Lauretis, 1994, p. 208). O paradoxo dessa produção, entretanto, está no fato de que os modos de vida que parcialmente escapam aos modelos prescritivos de gênero são geralmente classificados pelas normas regulatórias no âmbito da anormalidade. Isso contribui para reafirmar a existência de um campo em que determinadas composições de gênero são representadas como normais e adequadas (Butler, 2001).

Nessa perspectiva, partimos do pressuposto de que notícias sobre mulheres julgadas ou supostamente envolvidas na criminalidade operam no sentido de reafirmar e, ao mesmo tempo, desestabilizar modelos prescritivos de gênero. Com base nisso, problematizaremos o que denominamos como configurações subjetivas de mulheres envolvidas em situações de crimes e que, em alguma medida, rompem com a representação social de fragilidade, passividade e delicadeza. Estas, ao cometerem crimes, ganham espaço na mídia nacional, sendo descritas, de acordo com a pesquisa realizada, em torno das quatro configurações já citadas. Ainda que na problematização dos enunciados presentes nas reportagens coletadas tenhamos destacado essas quatro "personagens", consideramos a possibilidade de existência de outras configurações. Destaca-se, por fim, que os autores utilizados nas análises estão filiados ao debate das questões de gênero e ao questionamento da ordem capitalista hegemônica. 


\section{AS MULHERES CRIMINOSAS EM PAUTA: APRESENTAÇÃO DA ANÁLISE DOS DADOS}

\subsection{A VÍTIMA}

Uma figura recorrente nas notícias que circulam nas mídias impressa e digital é a da "criminosa vítima". Como "um conto de fadas com final às avessas" (Scott, 2012), os enunciados afirmam que tais mulheres foram levadas a cometer crimes em virtude de distúrbios psicopatológicos, amores incontroláveis e, ou, vivências de opressão, como elucida o trecho de matéria a seguir: "Antes de matar ou mandar matar, ela (mulher julgada como criminosa) passou por uma sucessão de agressões verbais ou físicas. O crime é a gota que transborda o copo" (Oliveira, \& Sampaio, 2002). Apresentadas comumente como resultado de uma explosão e, ou, de um momento de desespero, as práticas de mulheres no crime são descritas como "exceções". O pressuposto de que seus atos refletem situaçôes inevitáveis implica a presunção de que, caso houvesse outra saída, elas "naturalmente" não teriam cometido o delito. Desse modo, tais enunciados rearticulam um suposto "traço essencialista" que subjaz no corpo feminino e que o evoca como passivo (Costa, 1989).

Nessa perspectiva, a imagem de mães possuidoras de um "instinto materno" (Badinter, 1985) inalienável se apresenta como explicaçôes recorrentes para delitos cometidos, como elucida um trecho de entrevista publicada no jornal Folha de São Paulo em 2002, realizada por uma mulher que assassinou o marido agressor: "Quando sente que seus filhos estão ameaçados, a mãe os defende. Só pela minha vida eu não faria uma coisa dessas" (Oliveira \& Sampaio, 2002, p. 6). O enunciado evidencia que a intenção de proteger os filhos supera qualquer outro desejo, inclusive o da própria sobrevivência, o que se configura, em nosso entendimento, como um processo de "ortopedia moral" (Foucault, 1975/2011), visto que estabelece uma correlação direta (instintiva) entre feminilidade e maternidade.

O conceito de "instinto" emergiu como tema privilegiado na psiquiatria do século XIX, tendo se configurado como peça importante na trama de componentes que se intercruzaram na construção de noções de normalidade e anormalidade (Foucault, 1976/2010). O pressuposto de um instinto foi um vetor importante na associação da criminalidade à ideia de desvio de conduta, pois, a partir desse momento, as expressões de distúrbios e irregularidades foram sobrecodificadas como traços eminentemente individuais. Foucault (1976) analisa: "É a partir da noção do instinto que vai poder se organizar, em torno do que era outrora o 
problema da loucura, toda a problemática do anormal, do anormal no nível das condutas mais elementares e mais cotidianas" (pp. 112-113).

Ainda que o pressuposto da existência de um instinto "individualize" e descontextualize as práticas de crime, o enunciado tem efeitos generalizantes e totalizantes em torno de uma suposta "essência". Como um dos efeitos dessas articulaçōes, ressalta-se que, nos últimos séculos, o desenho de um novo modo de ser mãe esteve diretamente relacionado à premissa de um instinto materno inerente às mulheres (Badinter, 1985; Giddens, 1992/1993). Desde então, os filhos foram considerados objetos privilegiados de atenção feminina, sendo as mulheres apresentadas como as figuras responsáveis por garantirem suas sobrevivências. Em consonância à prerrogativa da maternidade, crimes de mulheres são geralmente mais aceitáveis e suportáveis quando cometidos em nome da proteção e amor aos filhos, como se pode verificar no trecho de uma matéria intitulada $O$ amor de mãe que produz atos chocantes:

Maria do Carmo Ghislotti teve seu filho de 3 anos violentado por um garoto vizinho. $\mathrm{Na}$ delegacia, quando o rapaz comentou que não ficaria preso por ser menor, Maria do Carmo saltou com uma faca na jugular dele, e o matou, num só golpe. Em seguida, deu as próprias mãos para serem algemadas, dizendo que tinha vingado seu filho e daria a própria vida por ele (Aggege, \& Mayrink, 2006, p. 32).

Ao acompanhar as publicações em relação ao caso de Maria do Carmo, notou-se que grande parte das notícias tendia a localizar seu ato como resultado da "mulher [que] se apaga em favor da boa mãe que, doravante, terá suas responsabilidades cada vez mais ampliadas" (Badinter, 1985, p. 206). Ainda que Maria do Carmo tenha premeditado o crime, seu ato foi relatado, na maioria das notícias, como um momento de descontrole, o que provavelmente interferiu no desfecho de seu julgamento: ela foi absolvida pelo Tribunal do Júri com a tese de que agira em nome da defesa e honra do filho.

$\mathrm{Na}$ problematização de notícias sobre crimes cometidos por mulheres, é notável a articulação de um campo moral de análise, sendo seus atos geralmente classificados como mais ou menos graves, dependendo de se aproximarem ou se distanciarem de prerrogativas tradicionais de feminilidade. Esse processo de moralização evidencia a comoção social que geralmente os casos de infanticídios cometidos por mulheres, sobretudo aquelas de classes média e alta, causam na população. Nesse sentido, destaca-se o caso da vendedora Simone Cassiano da Silva, acusada de ter colocado, no ano de 2006, a filha de três meses dentro de um saco plástico e a jogado na Lagoa da Pampulha, em Belo Horizonte. Notícias veiculadas durante o período de julgamento de Simone estiveram carregadas de comentários pejorativos que contribuíram para desenhar a imagem de 
uma mulher perversa e fria, como elucida o trecho: "Ficou claro que ela tinha motivaçôes para fazer aquilo e toda a defesa já caiu por terra. Comprovamos que ela mentiu. Nunca havia visto tanta frieza em uma criminosa contra a própria filha, recém-nascida" (Alves, 2007, p. 17).

Ao sobrecodificar a tentativa de homicídio como resultado de uma ação ocorrida em estado puerperal, o crime em questão ganha os contornos de um ato cometido por uma mãe desequilibrada em um momento de fragilidade e pressão emocional, restituindo assim a imagem da feminilidade normal como eminentemente materna. O pressuposto de estados psíquicos "anormais" (Foucault, 1976) tem sido amplamente empregado na mídia para explicar crimes cometidos por mulheres, sendo estes apresentados como atos cometidos em momentos de insanidade e de perda da consciência. Nesse sentido, vemos circular uma segunda figura bastante recorrente na mídia e que também contribui para representar a criminalidade feminina a partir do pressuposto de vitimização e anormalidade.

\subsection{A DESEQUILIBRADA}

São frequentes as notícias que tendem a correlacionar crimes cometidos por mulheres com a loucura. Ao analisar a linguagem criminológica constituída no século XIX, Faria (2008) verificou que as mulheres eram consideradas menos capazes de cometer delitos que os homens, sendo as práticas delas habitualmente circunscritas como desviantes. Constituindo-se como "meras falhas do desenvolvimento ou impossibilidades lógicas, precisamente porque não se conformarem às normas da inteligibilidade cultural" (Butler, 2003, p. 39), a explicação da criminalidade feminina como "ato de loucura" está articulada aos efeitos de um conjunto de poderes normalizadores. Foucault (1976) ressalta que, a partir do século XIX, a sobrecodificação da loucura como origem de toda ação criminosa legitimou uma aliança estratégica entre o poder judiciário e o poder médico, tendo se consolidado como uma importante engrenagem de controle e normalização social. A partir desse momento, o louco é considerado "aquele em que a delimitação, o jogo, a hierarquia do voluntário e do involuntário se encontram perturbados" (Foucault, 1976, p. 134), o que caracterizaria seus crimes como expressões de irracionalidade. Em consequência disso, deparamo-nos com notícias que associam crimes cometidos por mulheres a crises incontroláveis de ciúmes, depressões pós-partos, uso de drogas e distúrbios mentais. Esse é o caso da seguinte reportagem: "Roselani (acusada de matar o marido) é dona de uma fábrica de calçados na cidade. $\mathrm{O}$ delegado que preside o inquérito, Nauro 
Osório Marques, diz que ela estava em tratamento psiquiátrico contra depressão" ("Mulher é acusada", 2009). O pressuposto de depressão torna apreensível, senão suportável, o ato cometido por Roselani, pois a

Possibilidade de invocar a loucura excluía [. . . ] a qualificação de um ato como crime: na alegação de o autor ter ficado louco, não era a gravidade de seu gesto que se modificava, nem a sua pena que devia ser atenuada: mas o próprio crime desaparecia (Foucault, 1976, p. 23).

A presunção de "desvio" assume outro contorno: relacionar mulheres criminosas à infantilização, sendo elas apresentadas como meninas frágeis, desinformadas e assustadas. O enunciado de "imaturidade" se organiza no sentido de desresponsabilizá-las pelos delitos cometidos, como se suas condições as incapacitassem de entender e planejar os crimes em questão, como fica claro no trecho de matéria citado: "Ela é muito infantil, não tem noção da gravidade do ato que cometeu, não sabe que sequestro é crime hediondo" (Carvalho, 2001). Apresentadas como criminosas que cometeram atos de violência de modo "inocente", devido a sua condição infantilizada, os enunciados sugerem a ausência de noção da gravidade dos atos cometidos, como elucida a descrição: "Tão pequenas (adolescentes apreendidas por envolvimento no tráfico de drogas) que ainda fazem xixi na cama” (Aranda, 2009, p. 23).

Outro argumento bastante frequente na descrição de crimes cometidos por mulheres é o que posiciona seus atos como resultado de um amor incontrolável por um homem bandido, como exemplifica um trecho de matéria que questionou a participação de Suzane Von Richthofen no homicídio de seus pais:

O advogado de Suzane (julgada por coparticipação em crime de parricídio) vai alegar que Daniel manipulou a jovem. [.. . "A pergunta principal para o júri, principalmente para as mulheres, que entendem de virgindade e amor, é a seguinte: 'Se a Suzane não tivesse conhecido o Daniel, os pais dela estariam hoje mortos?”, questiona Nacif, que em seguida responde: "Jamais. Ela começou a brigar com os pais por causa dele, um explorador". [. . .] "Ela era uma mulher apaixonada, perdeu a virgindade com ele aos 16 anos, era uma escrava psíquica. Mulher apaixonada faz qualquer negócio”, disse Mauro Otávio Nacif (Takahashi, \& Soares, 2006).

A notícia apresenta Suzane como uma jovem frágil, perdida e manipulada pelo namorado. Ao destacar o envolvimento afetivo dessas mulheres como a explicação de sua participação na criminalidade, a mídia contribui para o reposicionamento do feminino enlaçado à dimensão do amor (Costa, 1989).

A justificativa do amor também foi associada ao instinto: uma "voz eloquente e poderosa”, uma "inclinação irreversível e indomável” (Costa, 1989, p. 230). 
Nessa perspectiva, haveria um instinto feminino que habita o corpo das mulheres. Isso implicou efeitos diretos nas maneiras como diversos aparatos midiáticos insistem em explicar o envolvimento de mulheres no crime como resultado de uma paixão desenfreada, instintiva, por um bandido, como elucida a notícia: "A cabeleireira Márcia de Freitas Salvador, 32, que confessou ter sequestrado um bebê em Curitiba, disse ontem que cometeu o crime 'por amor' a um ex-namorado, eleito por ela para ser o 'pai' da criança”' (Valle, 2005). Segundo Grossi (1998, p. 299), "O modelo de conjugalidade ocidental moderno" centra-se na categoria "universal" do amor, o que dificulta a apreensão de "modelos hegemônicos de gênero com os quais homens e mulheres dialogam permanentemente". Nesse sentido, o pressuposto do envolvimento de mulheres no crime apenas por amor implica tornar seu ato mais apreensíveis pela população, visto que reproduzem uma dimensão considerada inerente ao feminino, distanciando-o, novamente, da dimensão violenta e agressiva do ato.

Nas reportagens analisadas, encontrou-se um último argumento que frequentemente está presente nas descriçõos e depoimentos relacionados aos delitos cometidos por mulheres: a culpa e o arrependimento. Isso pode ser constatado no trecho a seguir: "A estudante Suzane Von Richthofen, que confessou ter participado do assassinato dos pais em 2002, está arrependida do crime e com saudades da família" (Hisayasu, 2005). O enunciado da criminosa desviante e perigosa afirma-se como correlato abjeto da imagem da mulher "normal", ou seja, a expressão de uma feminilidade anormal que opera necessariamente no dimensionamento de uma suposta feminilidade adequada (Butler, 2001). Trata-se de classificar as mulheres ditas anormais, de fixá-las e de prescrever-lhes espaços, condutas e limites claros. Trata-se, especialmente, de utilizá-las como modelos daquilo que a sociedade não deve seguir e que implica um possível risco para todos. Sobre isso, assinala Foucault (1973/2003, p. 85):

A noção de periculosidade significa que o indivíduo deve ser considerado pela sociedade ao nível de suas virtualidades e não ao nível de seus atos; não ao nível das infrações efetivas a uma lei efetiva, mas das virtualidades de comportamento que elas representam (p. 85).

\subsection{A PRIMEIRA-DAMA}

Nos últimos anos, são comuns as notícias sobre mulheres criminosas que optam por manter relações afetivas e conjugais apenas com homens envolvidos na criminalidade. Ao contrário das matérias sobre mulheres que foram "obrigadas" a cometer delitos em nome do amor descontrolado por um bandido, 
as chamadas "primeiras-damas" emergem da mídia como mulheres satisfeitas com as experiências de poder e status que o envolvimento afetivo com bandidos lhes possibilita. Isso fica evidente no fragmento: "A ambição de ter maior nível econômico e ser reconhecida leva muitas (mulheres) a se casarem com traficantes e desfilarem em carros de luxo" (Arêas, 2007).

As "primeiras-damas" são comumente apresentadas na mídia como mulheres sensuais, decididas e influentes, o que contribui para desestabilizar parcialmente os modelos tradicionais de gênero que representam as mulheres como seres frágeis e passivos (Butler, 2003). Entretanto, grande parte das notícias também anuncia suas escolhas e estilos de vida a partir de comentários jocosos e pejorativos, como expressões de mulheres fúteis, libertinas e frívolas. Nota-se, nessas associações, a localização da criminalidade entre as mulheres como expressões de incivilidade, impudor, indecência, desonestidade e, ou, inadequação as normas sociais. Os efeitos dos binarismos nas perspectivas tradicionais de gênero implicam que certas práticas sejam avaliadas como inconcebíveis. Assim, as tais mulheres são consideradas "seres abjetos" que se apresentam como "zonas 'inóspitas' e 'inabitáveis' da vida social, que são, não obstante, densamente povoadas por aqueles que não gozam do estatuto de sujeito, mas cujo habitar sob o signo do 'inabitável' é necessário para que o domínio do sujeito seja circunscrito" (Butler, 2001, p. 155).

Ao mesmo tempo em que composições de gênero se produzem na legitimação de normas sociais, elas são também desestabilizadas no curso dessa produção, sendo o sujeito constituído em meio à interferência de linhas de exclusão e abjeção, "uma força que produz um exterior constitutivo relativamente ao sujeito, um exterior abjeto que está, afinal, 'dentro' do sujeito, como seu próprio e fundante repúdio” (Butler, 2001, p. 156). Assim, considera-se que notícias sobre mulheres julgadas ou supostamente envolvidas na criminalidade operam no sentido de reafirmar e desestabilizar modelos prescritivos de gênero. Nessa perspectiva, chama a atenção, na maior parte das matérias analisadas, o fato de os crimes cometidos por essas mulheres estarem quase subjugados pela condição de "esposas", "namoradas", "parceiras", como se os delitos fossem meros detalhes na narrativa, tal qual aparece a seguir:

A mulher (Flávia dos Santos Lima) do bandido que ordenou o abate de um helicóptero da Polícia Militar, Fabiano Atanásio da Silva, o FB, hoje preso, adora ostentar suas correntes de ouro, várias ao mesmo tempo, e exibir pilhas de dinheiro vivo no meio da rua. Certa vez, apareceu em uma concessionária disposta a sair de carro novo. "Em questão de minutos, ela pagou 100000 reais em espécie por uma caminhonete preta”, conta um dos investigadores, que prendeu a moça dois meses atrás (Leitão, 2013). 
Nota-se que o fato de Flávia ter sido presa é quase irrisório no texto de abertura da notícia, sendo que o que está em evidência são as descrições que a relacionam a consumo, exibicionismo e certa atmosfera moral de desajuste às premissas tradicionais de feminilidade. As referências à sensualidade e a gastos de dinheiro em benefício próprio estão presentes na descrição das roupas curta e justa, nos seios quase à mostra, nas joias, brilhos e maquiagens. $\mathrm{O}$ enunciado opera no sentido de atualizar a prerrogativa de que mulheres que assumem modos de vida dissonantes às prerrogativas de gênero são necessariamente "promíscuas".

Outra questão a ser analisada é a presença de múltiplos personagens nas descrições, o que torna difusos os relatos dos crimes cometidos pelas primeiras damas:

É bem raro ver Márcia Gama dos Santos Nepomuceno no Complexo do Alemão, conjunto de favelas da Zona Norte onde seu marido, Márcio Nepomuceno, o Marcinho VP, permanece o comando da mais poderosa célula criminosa do Rio de Janeiro - mesmo estando preso desde 1996. Ela vive em uma mansão com os quatro filhos do casal, numa propriedade protegida por uma muralha de 3 metros de altura e cerca elétrica no bairro de Jacarepaguá, Zona Oeste da cidade. Com carrão e secretária, ela lava o dinheiro do marido (Leitão, 2013).

Embora o mote da matéria publicada na revista fosse sobre mulheres que ocupam posição de liderança no tráfico de drogas de favelas do Rio de Janeiro e São Paulo, o crime cometido por Márcia (lavagem de dinheiro) desaparece em meio às descrições sobre a condição atual do marido, os quatro filhos e a secretária. Ainda que Marcinho VP esteja na condição de preso e Márcia coordene as ações em um "conjunto" de favelas, o relato insiste em posicioná-lo como o bandido responsável pelas ações e Márcia como uma figura frágil que precisa ser protegida pelas muralhas erguidas e sustentadas pelo marido. Sendo apresentada como aquela que "lava o dinheiro do marido", Márcia é vista como responsável por cuidar dos interesses dele e não como criminosa capaz de encabeçar o tráfico de drogas.

Encontram-se também matérias que denominam as autoras de crimes valorizando suas vinculações conjugais e afetivas, como se essa fosse a explicação principal do envolvimento delas na criminalidade e como se, nessa conjuntura, elas sempre ocupassem o lugar de "ajudantes" de seus parceiros. Isso pode se verificar no trecho destacado: "Seios siliconados, mansões, apartamentos pagos em dinheiro vivo, joias, secretárias particulares: as mulheres de bandido cariocas que cumprem pena gastam dinheiro a rodo e ajudam os maridos a tocar seus negócios criminosos" (Leitão, 2013). O próprio título da matéria da Veja (Leitão, 2013), Herdeiras do tráfico, já pressupõe a incapacidade das mulheres 
em conquistar e, ou, gerenciar por conta própria os pontos de venda de drogas. Ainda que, na notícia, se afirme que as mulheres só assumem a liderança de facções criminais e de regiôes onde o tráfico de drogas se articula devido ao fato de seus maridos estarem presos, o relato das ações desenvolvidas por elas, como lavagem de dinheiro, homicídios, negociações com a polícia, entre outras operações, demonstram sua capacidade de comandar. Contudo assumem essa função apenas como "herdeiras" e "coadjuvantes".

Embora as descrições sobre as primeiras-damas deem visibilidade a novas experimentações de mulheres nos espaços públicos (e privados), o redimensionamento das práticas como resultado do envolvimento com homens implica a reprodução de noções tradicionais de gênero. Badinter (2005) argumenta que a delimitação de uma dominação masculina naturalizada e "eterna" recorre necessariamente na presunção de uma condição de "vítima feminina" também tida como natural. Ao analisar a conjuntura brasileira atual, Carvalho, Adelman e Rocha (2007) mantêm ressonâncias com a análise de Badinter quando dizem:

Herdeiras da tradição do olhar estabelecido nos alvores da sociedade burguesa moderna, em que os homens definiam e propagavam as convenções da representação feminina, as imagens que povoam as ruas e outros espaços públicos (e privados) da vida contemporânea conduzem para uma leitura da mulher como não sujeito (p. 124).

A ideia de que é sempre um homem o "mentor" e, ou, o motivo pelo qual uma mulher se envolveu numa ação criminal implica a afirmação do feminino como "incapaz", "submisso" e "ajudante". Na contraposição dessa construção, nota-se que dificilmente as notícias sobre crimes cometidos por homens abordam suas dimensões afetivas e conjugais, pois essas não são consideradas como justificativas para os atos cometidos. Nesse sentido, "As mídias acabam sendo veículos de eliminação ou reforço de posturas de subserviência ou submissão das mulheres em relação a posturas de dominação masculina e androcêntricas, na recorrência de imagens, textos e discursos" (Carvalho, Adelman, \& Rocha, 2007, p. 126).

Em contrapartida às imagens correlacionadas às primeiras-damas nos últimos anos, temos encontrado notícias sobre mulheres que ocupam posição de liderança em ações criminais, como se verifica em trechos das matérias seguintes: Mulheres no comando e na mira do tráfico (Arêas, 2007, p. 16) e Confronto revela "chefona" do tráfico no Rio (Martins, 2012). Sua posição de destaque deixa atônita grande parte da população, sendo que as tentativas de justificar seus atos como resultados da vinculação com um marido e, ou, do desejo por adotar um modo de vida representado como banal demonstram as dificuldades da sociedade em lidar com 
a evidência de que uma mulher tenha capacidade de se inserir na criminalidade por escolha e desejo.

\subsection{A EMANCIPADA}

A criminosa emancipada foi uma figura que apareceu pontualmente na mídia na segunda metade do século XX, encarnada inicialmente na história de Lili Carabina, uma mulher líder de uma gangue de assaltantes a banco. Desde então, temos nos deparado com algumas notícias de mulheres que anunciam o envolvimento na criminalidade como resultado de desejo e escolha própria, sem envolvimento como um homem e, ou, com uma condição de necessidade e opressão. Consideradas como mulheres "autônomas" e "fatais" (Oliveira, \& Sampaio, 2002), as "criminosas emancipadas" são apresentadas na mídia com as caracterizaçōes de prazer, poder e ambição, como se verifica no trecho de notícia destacado a seguir: "'O caso dela [Carina] é para ser estudado pela criminologia. Essa mulher deixava sua vida confortável em Curitiba para vir cometer crimes em São Paulo. Para ela, era uma aventura, pura adrenalina', disse o delegado Alberto Pereira Matheus Júnior" (Pagnan, \& Gama, 2012). No entanto, ainda que tais notícias estejam cada vez mais frequentes, nota-se que as vivências dessas mulheres permanecem, em grande medida, inapreensíveis pela maior parte da população. São como corpos ininteligíveis, obscenos, que elas são descritas nos aparatos midiáticos, causando sensação de confusão e perda de território.

Conhecida como "Kelly Ciclone", "Patroa do Tráfico" e "Dama do Pó", ela ficou famosa na Bahia pela ousadia com que transitava no mundo do crime e liderava ações criminais. Apresentada na mídia como uma mulher "ousada", "corajosa", "perspicaz" e "inteligente", alguns elementos utilizados para ilustrar Kelly reafirmam e desestabilizam premissas tradicionais de feminilidade (Butler, 2003). As diversas tatuagens espalhadas pelo corpo de Kelly, por exemplo, contribuem para embaralhar os códigos entre o masculino e o feminino, pois a imagem de dragão coexiste com a do coelho, símbolo da revista masculina Playboy, em sua barriga, e a frase tatuada nas costas "vida loka", que faz alusão e apologia aos modos como a vida se articula na criminalidade.

Kelly foi assassinada em julho de 2011, sendo encontrada sozinha e com diversos tiros e facadas pelo corpo. $\mathrm{O}$ fato de o autor do crime não ter sido pego em flagrante possibilitou a emergência de suposiçóes sobre os motivos do assassinato. Ainda que o extermínio seja prática recorrente no mundo do crime e que a morte dela tenha também sido correlacionada à sua posição de liderança no tráfico de drogas da região, a maior parte das notícias encontradas sugeria que 
o homicídio era fruto de um relacionamento passional ("Polícia aponta", 2011), o que novamente opera para associar o feminino à dimensão do amor, ainda que seja um amor considerado impróprio.

$\mathrm{Na}$ análise desse caso, questiona-se também o fato de Kelly estar envolvida na criminalidade na Bahia, o que torna seu envolvimento como "patroa do tráfico" ainda mais surpreendente e subversivo em uma das regiões vistas como mais machistas e conservadoras do Brasil (Sampaio, 2012). Contudo, acredita-se que, para a maior parte da população brasileira, o envolvimento de Kelly na criminalidade é, até certo ponto, justificada pela sua condição econômica de classe baixa, pois sendo a criminalidade comumente associada à pobreza (Abramovay, \& Fefferman, 2008), a "vida loka" está subjugada a processos de criminalização da pobreza. Tal associação, contudo, já não é tão facilmente estabelecida quando nos deparamos com casos de mulheres de classes média e alta que aparentemente optaram pela vida no crime. O destaque para as questóes de classe potencializa o estranhamento que o envolvimento de mulheres na criminalidade causa à sociedade. Isso foi verificado nas notícias sobre a "Gangue das Loiras", nome dado na mídia a um grupo de mulheres brancas de classes média e alta que cometeram mais de 50 sequestros-relâmpago entre os anos de 2008 a 2012. Sobre a atuação de uma das mulheres, membro da "Gangue", um policial comentou espantado: "A mulher e mãe zelosa, de voz doce, transformava-se numa violenta criminosa, de arma em punho e linguajar chulo na boca” (Pagnan, \& Gama, 2012). Notase que, ao lado do estranhamento de que uma mulher seja capaz de cometer um crime, a condição de classe também opera como um elemento que torna os crimes dessas mulheres quase inapreensíveis à sociedade, por se constituírem como expressões de desejos posicionados como pervertidos e inadequados a um corpo feminino.

Segundo Carvalho et al. (2007, p. 125), a visibilidade de figuras híbridas, por exemplo, as "emancipadas", estão também relacionadas às dimensões raciais. Os crimes de mulheres brancas, de classes média e alta, que participam ativamente do mercado de trabalho, apesar de não abandonarem as responsabilidades do lar, geralmente ganham maior espaço e repercussão nas instâncias midiáticas. Tais enunciados contribuem para veicular as noções de desejo e autonomia como sendo exclusivas de classes favorecidas.

Outros elementos estão presentes nas notícias sobre "criminosas emancipadas" e tendem a subjugar sua capacidade de cometer delitos. São frequentes as descriçōes físicas pormenorizadas dessas criminosas (altura, cor do cabelo, peso, beleza) e a narração das maneiras como elas se vestem, em detrimento da 
explanação das condições em que os crimes delas ocorreram. Isso é elucidado no trecho a seguir: "Morena, com 56 quilos distribuídos em 1,76 metro, furtava dinheiro, cheques, cartões de crédito e objetos de arte" (França, 2014).

Ao fim da descrição dessas quatro figuras, pode-se dizer que as últimas décadas têm sido marcadas por novas tecnologias comunicacionais, instrumentais e sociais que fazem circular novos saberes, afetos, símbolos, linguagens e formas de vigilância. Em meio a essa diversidade, os aparatos tecnológicos participam cada vez mais diretamente da produção das subjetividades. Nesse sentido, afirma Haraway (2000, p. 6): "Nossas máquinas são perturbadoramente vivas e nós mesmos assustadoramente inertes".

\section{CONSIDERAÇŌES FINAIS}

As tecnologias globais de comunicação invadem o cotidiano e participam da difusão de estilos de vida, colocando em circulação novos regimes de subjetivação e controle que atualizam um campo complexo de guerra entre as fronteiras de gênero. Ainda não sabemos os efeitos subjetivos trazidos por tais tecnologias, mas é evidente que elas colocam em curso modos de existir díspares, nem sempre fáceis de serem acolhidos e elaborados pela população.

No decorrer desta pesquisa, foi possível detectar o quanto a mídia tem dificuldades em compreender parte dos elementos sociais e subjetivos em trânsito nas últimas décadas. É perceptível, por exemplo, a presença de análises baseadas em premissas tradicionais de gênero pautadas em enfoques psicopatologizantes e, ou, morais, que estão presente na maioria das reportagens. Destacamos, assim, as dificuldades de alguns jornalistas, bem como de pesquisadores, ativistas no campo dos estudos de gênero e da população em geral, em questionar, de forma crítica e sensível, as fronteiras binárias marcadas por pressupostos naturalizantes de masculinidade e feminilidade. Dessa forma, mulheres e homens tendem a ser representados em um campo dual, universal e hierárquico, no qual, respectivamente, um se apresenta como vítima e frágil, e o outro, como opressor, racional e viril.

Parte dos enunciados cartografados nesta pesquisa acerca das quatro personagens selecionadas (a vítima, a desequilibrada, a primeira-dama e a emancipada), entretanto, faz entrever movimentos de experimentação que são ensaiados na vida cotidiana. Destacamos, por exemplo, que alguns dos relatos cartografados de mulheres que transitam no campo da criminalidade, como as ditas criminosas emancipadas, elucidam composições que desestabilizam 
prerrogativas tradicionais de feminilidade, provocando fissuras nos sistemas de sexo-gênero. A presença dessas configurações aciona na população vivências, sensações e percepções díspares que a expõem ao contato com outros modos de vida.

Configurações de gênero nem sempre se constituem de maneira visível, coerente e condizente aos modelos de inteligibilidade cultural, tão naturalizados. Considerar o envolvimento de mulheres na criminalidade possibilita vislumbrar que as análises binárias de gênero tornam inapreensíveis alguns elementos que colocam em curso modos plurais de existência. Cabe considerar que os processos de produção subjetiva ocorrem em meio a um conjunto de arranjos sociais, culturais, tecnológicos e políticos que interpelam diariamente a população. Desse modo, ao localizar as perspectivas de gênero como produções enlaçadas às tecnologias globais de comunicação, este artigo buscou aliar-se a discursos, imagens e movimentos que, na atualidade, buscam implodir as noções binárias circunscritas em torno de categorias estanques, como sujeito e objeto, natural e artificial. Isso nos permitiu dar visibilidade à guerra instalada na fronteira dos gêneros, cujos efeitos, por serem móveis e transitórios tal como anunciado por Foucault, dão movimento aos modos de vida.

Em um momento histórico que tende ao controle sistemático e naturalizado da vida e, em larga medida, ao julgamento moral e conservador das diferenças, acreditamos que a potência política desta pesquisa consistiu, precisamente, em dar visibilidade e problematizar as experiências de mulheres que se encontram na criminalidade, evidenciando existências fronteiriças, paradoxais e híbridas. Consideramos, portanto, que as tensões presentes nas fronteiras de gênero colocam em curso novos modos de subjetivação, exigindo outras leituras sobre a existência. 


\section{REFERENNCIAS}

Abramovay, M., \& Fefferman, M. (2008). Se ficar o bicho come. Revista Super, 8, 56-67.

Aggege, S., \& Mayrink, I. (2006, 12 dezembro). O amor de mãe que produz atos chocantes. $O$ Globo, 32.

Alves, A. (2007, 17 janeiro). Mãe acusada de tentar matar bebê vai a júri popular em MG. O Globo, 17.

Aranda, F. (2009, 27 julho). Tão pequenas que ainda fazem xixi na cama. $O$ Estado de São Paulo, 23.

Arêas, C. C. (2007, 7 outubro). Mulheres no comando e na mira do tráfico. Jornal do Brasil, 16.

Avansini, C. (2012, 6 maio). Número de presas cresce 108\% no Paraná. Folha de Londrina, 8.

Badinter, E. (1985). Um amor conquistado: o mito do amor materno. Rio de Janeiro: Nova Fronteira.

Badinter, E. (2005). Rumo equivocado: o feminismo e alguns destinos. V. Ribeiro. Trad.). Rio de Janeiro: Civilização Brasileira.

Barros, L. P., \& Kastrup, V. (2015). Cartografar é acompanhar processos. In E. Passos, V. Kastrup, \& L. Escóssia (Orgs.), Pistas do método da cartografia: pesquisa-intervenção e produção de subjetividade. (pp. 17-31). Porto Alegre: Sulina.

Butler, J. (2001). Corpos que pesam: sobre os limites discursivos do "sexo". In G. L. Louro (Org.), O corpo educado: pedagogias da sexualidade. (pp. 151-172). Belo Horizonte: Autêntica.

Butler, J. (2003). Problemas de gênero: feminismo e subversão da identidade. Rio de Janeiro: Civilização Brasileira.

Carvalho, M. C. (2001, 21 agosto). Sou traficante, mas não sequestrei o bebê, diz T., 12. Folha de São Paulo, C3.

Carvalho, M. G., Adelman, M., \& Rocha, C. T. C. (2007). Apresentação. Estudos Feministas, 15(1), p. 123-130. 
Costa, J. F. (1989). Ordem médica e norma familiar. Rio de Janeiro: Graal.

De Lauretis, T. (1994). A tecnologia do gênero. In H. B. Holanda (Org.), Tendências e impasses: o feminismo como crítica cultural. (pp. 206-242). Rio de Janeiro: Rocco.

Deleuze, G., \& Guattari, F. (1996). Mil platôs: capitalismo e esquizofrenia. Rio de Janeiro: Ed. 34.

Faria, T. D. (2008). Mulheres no tráfico de pessoas: vítimas e agressoras. Cadernos Pagu, 31, 151-172.

Foucault, M. (1969/1986). A arqueologia do saber. Rio de Janeiro: Forense, 1986. (Publicado originalmente em 1969).

Foucault, M. (1973/2003). A verdade e as formas jurídicas. Rio de Janeiro: NAU, 2003. (Publicado originalmente em 1973).

Foucault, M. (1975/2011). Vigiar e punir: história da violência nas prisões. Petrópolis: Vozes, 2011. (Publicado originalmente em 1975).

Foucault, M. (1976/2010). Os anormais. São Paulo: Martins Fontes, 2010. (Publicado originalmente em 1976).

França, V. (2014). Kelly, a sedutora de português ruim, enganou até seu advogado. O Estado de São Paulo. Recuperado a partir de http://brasil.estadao. com.br/noticias/geral,kelly-a-sedutora-de-portugues-ruim-enganou-ate-seuadvogado, 41074

Giddens, A. (1992/1993). A transformação da intimidade: sexualidade, amor e erotismo nas sociedades modernas. São Paulo: Ed. Universidade Estadual Paulista.

Grossi, M. P. (1998). Rimando amor e dor: reflexões sobre a violência no vínculo conjugal. In J. Pedro, \& M. P. Grossi (Orgs.), Masculino, feminino, plural. (pp. 293-313). Florianópolis: Mulheres.

Haraway, D. (2000). Manifesto ciborgue: ciência, tecnologia e feminismo socialista no final do século XX. In T. T. Silva (Org.), Antropologia do ciborgue: as vertigens do pós-humano. (pp. 37-129). Belo Horizonte: Autêntica.

Hisayasu, A. (2005, 2 julho). Suzane está arrependida, afirma advogada. Folha de S. Paulo, C5.

Leitão, L. (2013, 18 janeiro). Herdeiras do tráfico. Veja. 
Martins, M. A. (2012, 7 outubro). Confronto revela última 'chefona' do tráfico no Rio. Folha de S. Paulo, C9.

Mulher é acusada de matar marido, irmã e sobrinha no RS. (2009, 16 abril). Folha de S. Paulo, C4.

Oliveira, R., \& Sampaio, P. (2002, 17 novembro). Mulheres fatais. Folha de São Paulo, 6-10. Recuperado a partir de https://acervo.folha.com.br/leitor. 